\title{
Left or Right Screen Orientation in Endoscopic Ultrasonography?
}

\author{
Bendetto Mangiavillano ${ }^{a, b}$ Francesco Auriemma ${ }^{a}$ Alessandro Repici ${ }^{b, c}$

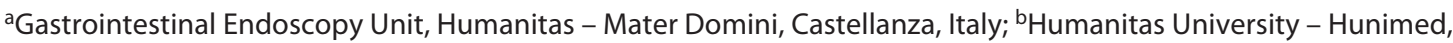 \\ Pieve Emanuele, Milan, Italy; ' Digestive Endoscopy Unit, Humanitas Research Hospital, Rozzano, Italy
}

Dear Editor,

Endoscopic ultrasonography (EUS) is a well-established endoscopic technique, starting at the end of the 70 s with the radial scan and evolving during the last years to linear diagnostic and subsequently to an operative tool. Currently EUS, in addition to still having a diagnostic role, has a pivotal part in the palliative management of neoplastic patients, especially with the introduction in the field of endoscopy of the lumen-apposing metal stent, allowing us to create anastomosis between pseudocysts or biliary tree and the GI lumen or to create gastrojejunal anastomosis. Different are the devices developed in the last years for therapeutic EUS, like coil for the gastric varices or needles for radiofrequency ablation for the treatment of advanced pancreatic cancer, neuroendocrine tumor, or neoplastic recurrence of the lower GI tract $[1,2]$. The two most relevant societies of gastrointestinal endoscopy (ASGE and ESGE) have launched in their guidelines the quality indicators for diagnostic and therapeutic EUS $[3,4]$, but it is not currently standardized what the correct screen orientation of the "near point" on the EUS image on the screen is. There are 2 different schools regarding the screen orientation of the EUS image, the left and the right side. Endosonographers who prefer the vision from the left side of the screen have

karger@karger.com

www.karger.com/ddi

(c) 2020 S. Karger AG, Basel

Karger! generally transabdominal ultrasonography experience, meanwhile endosonographers preferring the image starting on the right side of the screen are generally performing EUS as a clinician, without prior experience in transabdominal ultrasonography. These 2 different ways of screen orientation of the EUS image could result in a delay of fellows' learning curve. It could happen because most of the GI endoscopy fellows often have training in other EUS referral centers of the same country, or abroad, with a different screen orientation. The major problem is encountered when the fellow comes back. If the EUS vision learned outside is different from the one of their hospital, the learning curve is inevitably longer because they can encounter difficulties in switching the EUS screen to the other side. It could be traduced in a procedure-time lengthening that impacts on the number of procedures/day performed in their endoscopy unit. The same problem could be translated during the live congresses or live-streaming procedure; not all of the people attending the live session have the same EUS screen orientation as the operator. This issue was recently addressed by a group of researchers in EUS, concluding that screen orientation probably does not directly affect the performance of EUS [5]. In our opinion, this consideration could be correct in case of experienced endo- 
sonographers, and not during the learning curve of endoscopists approaching this technique. Moreover, endosonographers skilled in one of the 2 different screen orientations often experience difficulties in switching to the other. We hope and believe that in the near future, with the aid of the major GI endoscopy societies, the EUS screen orientation could be standardized worldwide.

\section{Disclosure Statement}

The authors have no conflicts of interest to declare.

\section{Funding Sources}

The authors have no founding source to declare.

\section{References}

1 Braden B, Gupta V, Dietrich CF. Therapeutic EUS: new tools, new devices, new application. Endosc Ultrasound. 2019;8:370-81.

2 Mangiavillano B, Khashab MA, Tarantino I, Carrara S, Semeraro R, Auriemma F, et al. Success and safety of endoscopic treatments for concomitant biliary and duodenal malignant stenosis: a review of the literature. World J Gastrointest Surg. 2019;11:53-61.
3 Coe SG, Raimondo M, Woodward TA, Gross SA, Gill KRS, Jamil LH, et al. Quality in EUS: an assessment of baseline compliance and performance improvement by using the American Society for Gastrointestinal Endoscopy-American College of Gastroenterology quality indicators. Gastrointest Endosc. 2009; 69:195-201.
4 Domagk D, Oppong KW, Aabakken L, Czakó L, Gyökeres T, Manes G, et al. Performance measures for ERCP and endoscopic ultrasound: a European Society of Gastrointestinal Endoscopy (ESGE) Quality Improvement Initiative. Endoscopy. 2018;50:1116-27.

5 Dietrich CF, Arcidiacono PG, Braden B, Burmeister S, Carrara S, Cui X, et al. What should be known prior to performing EUS exams? (Part II). Endosc Ultrasound. 2019;8:360-9. 